Journal of Accident and Emergency Medicine 1995 12, 216-217

\title{
Thermal injury to the upper aerodigestive tract after microwave heating of food
}

\author{
G.J. OFFER, D. NANAN \& J.N. MARSHALL
}

Accident and Emergency Department, Leicester Royal Infirmary NHS Trust, Leicester, UK

\section{SUMMARY}

Microwave-heated food may cause serious injury if it is not allowed to cool before consumption.' We describe a case in which a hypopharyngeal burn occurred following consumption of a microwave-heated potato immediately after cooking.

Keywords: dysphagia, foreign body, indirect laryngoscopy, microwaves, throat

\section{CASE REPORT}

A 21-year-old male student presented to the Accident and Emergency (A\&E) department complaining that a piece of jacket potato had lodged in his throat. He had heated a potato in a microwave oven and had eaten it immediately. Whilst eating, he suffered acute discomfort, following which a piece of potato had been regurgitated. He was then able to continue his meal. Five hours later, he presented with dysphagia for solids and liquids, and a persistent foreign-body sensation in his throat. He felt that he had difficulty in breathing.

Examination of the oropharynx was normal and there was no stridor. Indirect laryngoscopy revealed oedema of the epiglottis, hypopharynx and pyriform fossae. A lateral soft tissue radiograph was normal. Laryngo-pharyngoscopy under general anaesthesia revealed oedema and erythema consistent with thermal injury to the epiglottis and hypopharynx. The upper

Correspondence: Graham J. Offer, Senior House Officer, Accident and Emergency Department, Leicestep Royal Infirmary, Leicester LE1 5WW, UK oesophagus and vocal cords were normal, but the false cords were hyperaemic. A nasogastric tube was passed and intravenous steroids given. The patient was observed for signs of airway compromise. Recovery was uneventful and the patient was discharged on the third day after admission.

\section{DISCUSSION}

Microwave ovens generate heat deep within food, and this heat is transferred by conduction and convection throughout the food item. Thus cooked food may be cooler on the outside than on the inside. Failure to appreciate the differentially heated property of microwaved food may lead to injuries. Microwave-oven manufacturers advise that food is left to stand for a period of time, usually $2 \mathrm{~min}$, to allow the heat energy to diffuse evenly throughout the item. Pre-packaged food for microwave cooking often has a similar instruction on the packaging, but the reason for allowing the food to stand for his period of time is not stated.

Particular care must be taken with items that have a liquid centre, since the higher the water content, the more microwave energy is absorbed. An especially high risk is associated with the ingestion of microwave-heated baby-milk formulae. ${ }^{2}$ Parents may not appreciate the danger, as the outside of the container feels cool. Intraoral scalds from tea have also been reported. ${ }^{3}$

Burns to the upper aerodigestive tract may cause airway compromise, and this risk is often greatest several hours after injury, as oedema increases. Goldberg ${ }^{4}$ described a case of laryngeal burns following ingestion of microwaved potato in the USA, but we have found no such case previously reported in the literature in the UK Perlman ${ }^{5}$ described a case of oesophageal burns occurring after ingestion of a microwaved 'jelly-filled doughnut'. Again the item had not been allowed sufficient time to cool and had not felt excessively hot externally. Leiberman and Keefe ${ }^{6}$ reported a case of a microwaved jelly-filled pastry causing oesophageal burns.

Microwave ovens are now commonly used in both domestic and commercial food preparation. It is important that A\&E staff bear this type of injury 
Hypopharyngeal burn caused by microwave-heated food in mind when dealing with patients presenting with dysphagia or persistent foreign-body sensation after eating microwave-heated foods.

\section{REFERENCES}

1. Budd R. (1992) Burns associated with the use of microwave ovens. Journal of Microwave Power and Electromagnetic Energy 27, 160-163.

2. Hibbard R.A. \& Blevins R. (1988) Palatal burn due to bottle warming in a microwave oven. Pediatrics 82 , 382-384.
3. Garland J.S., Rice T.B. \& Kelly K.J. (1986) Airway burns in an infant following aspiration of microwave heated tea. Chest 90, 621-622.

4. Goldberg R.M., Lee S. \& Line W.S. Jr (1990) Laryngeal burns secondary to the ingestion of microwave heated food. Journal of Emergency Medicine 8, 281-283.

5. Perlman A. (1980) Hazards of a microwave oven. New England Journal of Medicine 302, 970-971.

6. Leiberman D.A. \& Keefe E.D. (1982) Esophageal burn and the microwave oven. Annals of Internal Medicine 97, 137. 